\title{
Disruption of Staphylococcus aureus biofilms using rhamnolipid biosurfactants
}

\author{
S. S. e Silva, ${ }^{*}$ J. W. P. Carvalho,† C. P. Aires, $\ddagger$ and M. Nitschke ${ }^{* 1}$ \\ *Department of Physical Chemistry, São Carlos Institute of Chemistry, University of São Paulo, Avenida Trabalhador São Carlense, 400, \\ Caixa Postal 780, CEP 13560-970, São Carlos, SP, Brazil \\ †Faculty of Architecture and Engineering, State University of Mato Grosso, Rua A, s/n, Cohab São Raimundo, Caixa Postal 92, CEP 78390-000, \\ Barra do Bugres, MT, Brazil \\ ‡Department of Physics and Chemistry, School of Pharmaceutical Sciences of Ribeirão Preto, University of São Paulo, Avenida do Café s/n, \\ CEP 14040-903, Ribeirão Preto, SP, Brazil
}

\section{ABSTRACT}

Staphylococcus aureus is an important pathogen that has shown ability to establish biofilm communities that can represent a source of contamination and resistance in food processing. Rhamnolipids (RL) have attracted attention as candidates to replace synthetic surfactants, exhibiting high surface activity combined with its microbial origin, biodegradability, and low toxicity. In this work, an RL biosurfactant was evaluated regarding its ability to disrupt or remove $S$. aureus biofilms established on polystyrene plates using nutrient broth and skim milk as the growth media. Rhamnolipid treatment was performed at different surfactant concentrations and temperatures. Rhamnolipid removes up to $88.9 \%$ of milk-based biofilms, whereas for nutrient medium $35 \%$ removal was attained. The RL concentration affects the disruption of nutrient medium-based biofilms. High carbohydrate content of milk-based biofilms favors disruption by RL and the organization of RL molecules in solution showed a predominance of aggregates from 1 to 10 and 100 to 1,000 nm in all conditions studied. Biofilm disruption activity of RL is nutrientspecific and dependent on biofilm matrix composition. Staphylococcus aureus biofilms established in milk were significantly reduced using RL at low concentrations and temperatures. These findings suggest potential application of RL in milk (dairy) processing industries where low temperatures are applied.

Key words: biofilm, milk, rhamnolipid, Staphylococcus aureus

Received April 12, 2017

Accepted July 10, 2017.

${ }^{1}$ Corresponding author: nitschke@iqsc.usp.br

\section{INTRODUCTION}

Food-borne diseases (FBD) are of great public health concern and are defined by World Health Organization as illnesses caused by the ingestion of food or drink contaminated with microorganisms or chemicals (WHO, 2016). The main microbial agents involved in FBD are bacteria and viruses; among bacterial pathogens, Staphylococcus aureus is one of the most relevant (Newell et al., 2010; USDA, 2013). Staphylococcus aureus has the ability to grow and produce heat-stable toxins in food products that, if consumed, can cause staphylococcal food poisoning, a common and widespread FBD (Argudín et al., 2010; Kadariya et al., 2014). Examples of food involved in staphylococcal food poisoning include meat, poultry and eggs, dairy and milk products, as well cream-filled bakery products (Hennekinne et al., 2012).

In Brazil, FBD were responsible for 886 outbreaks, resulting in 15,700 illnesses and 9 deaths in 2014. Staphylococcus aureus was the causative agent in $7.7 \%$ of total registered cases and $3.4 \%$ of outbreaks were associated with dairy products. However, this number could be much higher, as over than $50 \%$ of food and agents involved in FBD were not identified (SVS, 2015). According to Centers for Disease Control and Prevention, the dairy products were involved in $21 \%$ of food outbreaks in the United States in 2013 (CDC, 2013).

Besides planktonic living, many microorganisms are able to colonize surfaces establishing a sessile form of life known as biofilms. Biofilms can be defined as a microbial community surrounded by a self-produced polymeric matrix which are attached to biotic or abiotic surfaces (Costerton et al., 1999). The polymeric matrix protects microorganisms present in biofilms, making them more resistant to biocides and cleaning procedures compared with planktonic cells (Donlan and Costerton, 2002).

In food processing, biofilm formation is of great concern, as biofilms are a microbial reservoir that can 
cause equipment damage, food spoilage, and public health problems and are considered the major source of contamination in food (Simões et al., 2010; Abdallah et al., 2014). The presence of nutrients derived from food residues combined with adequate environmental conditions improves the growth and attachment of bacteria to surfaces; therefore, biofilms have been reported in different foods such as dairy, fish, poultry, meat, and ready-to-eat food (Srey et al., 2013; Abdallah et al., 2014). Moreover, raw food, such as milk, has a natural microbiota that can perform initial attachment to surfaces favoring the anchoring of contaminant bacteria to the biofilm (Marchand et al., 2012). Strategies to prevent or eradicate biofilms include physical, chemical, or biological treatments (Yang et al., 2012; Rendueles and Ghigo, 2012), and also the development of new surface-coated or modified materials to avoid biofilm establishment (Sadekuzzaman et al., 2015). The growing demand for sustainable technologies increases the interest in bio-based or green solutions to control biofilms, especially due to their ecofriendly and natural character (Satpathy et al., 2016). Within this context, microbial-derived surfactants or biosurfactants have been studied as alternative antibiofilm agents.

Lipopeptides and glycolipids are the main classes of biosurfactants that have been reported to prevent and control microbial biofilms (Banat et al., 2014). Actually, most of the work exploring antibiofilm activity of biosurfactants are relative to human biofilm pathogens; however, some examples of antiadhesive (Shakerifard et al., 2009), antimicrobial (Araújo et al., 2016), and biofilm disruption activity (Gomes and Nitschke, 2012) against food pathogenic bacteria have also been described.

Rhamnolipids (RL) are glycolipid surfactants produced by Pseudomonas spp. that have shown ability to disrupt biofilms of Staphylococcus aureus, Salmonella Enteritidis, and Listeria monocytogenes. Previous studies suggested that biofilm disruption activity of RL may be dependent not only on microbial strains involved, but also surfactant treatment conditions (Gomes and Nitschke, 2012). Moreover, a lack of studies exist regarding biofilms established in food matrixes, essential information for prospective application of biosurfactants in the food industry.

The aim of the current study was to evaluate the effect of temperature and RL concentration on the disruption of $S$. aureus biofilms established in polystyrene surfaces using nutrient broth and skim milk as growth media. Molecular distribution and organization of RL molecules under different conditions were also investigated.

\section{MATERIALS AND METHODS}

\section{Bacteria and Culture Media}

The food isolate Staphylococcus aureus ATCC 8095 was cultivated in nutrient broth or nutrient agar (both from Himedia, Mumbai, India) and incubated at $37^{\circ} \mathrm{C}$ for $24 \mathrm{~h}$. Final pH was adjusted to 7.4 and sterilization performed by autoclave at $121^{\circ} \mathrm{C}$ for $20 \mathrm{~min}$.

\section{Preparation of Bacterial Suspension}

Bacteria from stock medium were inoculated on nutrient agar at $37^{\circ} \mathrm{C}$ for $24 \mathrm{~h}$ and biomass was scraped from plate after addition of $5 \mathrm{~mL}$ of saline solution $(\mathrm{NaCl} 0.86 \%)$. Suspension was centrifuged at $8,000 \times$ $g$ at room temperature for $10 \mathrm{~min}$. After washing, the cell mass was standardized to approximately $1 \times 10^{9}$ cfu/mL (Raja et al., 2011; Araújo et al., 2016) and this suspension was used as inoculum to biofilm formation.

\section{Biosurfactant}

Rhamnolipids (purity 99\%, CAS Registry Number: 147858-26-2) were purchased from Rhamnolipid Inc. (Tampa, FL) as a stock solution containing 25\% (wt/ vol) of RL. The RL solutions used were prepared by dilution in distilled water and further sterilized by filtration $(0.22 \mu \mathrm{m})$.

\section{Biofilm Formation}

The media used for biofilm growth were nutrient broth and skim milk. Commercial skim milk powder (Elegê S/A, Teutônia, Brazil) was prepared at 10\% (wt/vol) in distilled water and sterilized at $121^{\circ} \mathrm{C}$ for $10 \mathrm{~min}$; final $\mathrm{pH}$ was 6.5 and was not adjusted. The biofilms were stablished on 96-well polystyrene microplates. The wells were filled with $180 \mu \mathrm{L}$ of nutrient broth or milk, inoculated with $20 \mu \mathrm{L}$ of the bacterial suspension, and incubated at $37^{\circ} \mathrm{C}$ for $48 \mathrm{~h}$ (Gomes and Nitschke, 2012).

\section{Surfactant Treatment}

After $48 \mathrm{~h}$ of growth, the medium was removed, biofilms were washed twice with distilled water, and the wells were filled with $200 \mu \mathrm{L}$ of RL solution previously prepared at different concentrations $(0.05,0.1,0.25$, $0.5,1$, and $2 \%)$. The surfactant treatment was performed at 4,25 , and $37^{\circ} \mathrm{C}$ for $2 \mathrm{~h}$ (Gomes and Nitschke, 2012). After surfactant removal, the wells were washed (as described above) and biofilms quantified. 


\section{Biofilm Quantification}

Biomass was quantified using the crystal violet staining method (Mireles II et al., 2001). The biofilms were fixed with $200 \mu \mathrm{L}$ of methanol for $15 \mathrm{~min}$ and stained for $15 \mathrm{~min}$ with crystal violet $0.5 \%$ (wt/vol). The wells were washed and filled with $200 \mu \mathrm{L}$ of acetic acid $33 \%$ (vol/vol). The optical density (OD; $630 \mathrm{~nm}$ ) was measured using a microplate reader (Enspire-PerkinElmer, Waltham, MA). The mean absorbance was used to calculate the percentage of biofilm removal according to the equation

$$
\begin{gathered}
\text { Percentage removal }(\%)=100 \\
-[(\text { OD experimental well/OD control well }) \times 100] .
\end{gathered}
$$

\section{Contact Angle Measurements}

The wettability of biofilms was evaluated by contact angle measurements. Polystyrene samples $(2.4 \times 7.6$ $\times 0.1 \mathrm{~cm})$ were cleaned as described by Zeraik and Nitschke (2010). The biofilms were established and treated with RL as previously described. As a control, samples of polystyrene with and without biofilms were immersed in distilled water for $2 \mathrm{~h}$. The contact angle of water was assessed by the sessile drop technique at $25^{\circ} \mathrm{C}$ on a goniometer (CAM 200, KSV Instruments Ltd., Helsinki, Finland) using a drop volume of $3 \mu \mathrm{L}$.

\section{Biochemical Characterization of Biofilm Matrix}

Biofilms were established on polystyrene samples (7.6 $\times 2.4 \times 0.1 \mathrm{~cm})$ as described above and treated for 2 $\mathrm{h}$ with RL at defined concentrations and temperatures. Biofilms were washed, immersed in saline solution $(\mathrm{NaCl} 0.86 \%)$, sonicated $(40 \mathrm{~Hz})$ in an ultrasonic water bath (Thornton $\mathrm{T} 740^{\mathrm{M}}$; Thornton-Inpec, Vinhedo, Brazil) for 5 min to detach the polymeric matrix, and lyophilized. The dry matrix material was dissolved in distilled water and submitted to biochemical analysis. The total carbohydrate content was determined by the phenol-sulfuric acid assay (Dubois et al., 1956) using glucose as standard. The protein was measured by the Lowry method with BSA as standard and the DNA concentration was measured using a spectrophotometer at $260 \mathrm{~nm}$ (NanoDrop 1000, Thermo Fisher Scientific, Waltham, MA)

\section{Dynamic Light Scattering of RL}

The dynamic light scattering (DLS) technique was employed to measure the size of the RL aggregates formed at different concentrations and temperatures.
The instrument Zetasizer Nano ZS (Malvern Instruments Limited, Worcestershire, UK) was used at a $173^{\circ}$ scattering angle. The intensity, particle number size distributions curves, and polydispersity index (PDI) were calculated using the software provided with the Zetasizer. Due to the limitations of the equipment, the lowest temperature used was $10^{\circ} \mathrm{C}$.

\section{Scanning Electron Microscopy}

Biofilms of $S$. aureus treated with biosurfactant and their respective controls were visualized by scanning electron microscopy. The dehydration procedure was carried out with increasing concentrations of ethanol: water as described by Zeraik and Nitschke (2010). The samples were maintained desiccated until gold sputtering and visualized by a scanning electron microscope (LEO 440, Zeiss, Cambridge, UK) operating at $15 \mathrm{kV}$.

\section{Confocal Laser Scanning Microscopy}

Biofilm architecture in the presence and absence of RL was visualized by confocal microscopy. Biofilms were established on polystyrene coupons $(5.0 \times 5.0$ $\times 0.1 \mathrm{~cm}$ ), treated with RL, and washed to remove unbound cells. Bacterial biofilms were stained with LIVE/DEAD BacLight Biofilm Viability kit (Molecular Probes, Life Technologies, Carlsbad, CA) according to manufacturer specifications and incubated at $37^{\circ} \mathrm{C}$ for $30 \mathrm{~min}$ in the dark. Images were acquired with an inverted microscope (LSM 780, Zeiss) and processed using the equipment software.

\section{Statistical Analyses}

Results were expressed as the mean of at least 3 independent replicates. The data were analyzed by ANOVA, and the means were compared using the Tukey test with the significance level fixed at $P<0.05$.

\section{RESULTS AND DISCUSSION}

\section{Biofilm Disruption Using RL}

The ability of RL to remove $S$. aureus biofilms was strongly dependent on the nature of culture medium. Biofilms established in nutrient broth were less susceptible to RL treatment, and the best results were obtained at $25^{\circ} \mathrm{C}$ and $0.1 \%$ concentration, which reduced around $35 \%$ of biofilm mass after $2 \mathrm{~h}$ under static conditions (Table 1). When nutrient broth was used as culture medium, the increase in RL concentration reduced biofilm disruption activity independently of the temperature 
Table 1. Percentage of Staphylococcus aureus biofilm removal after $2 \mathrm{~h}$ of treatment with rhamnolipids (RL) at different concentrations and temperatures

\begin{tabular}{llccc}
\hline & & \multicolumn{3}{c}{ Removal $(\%)$} \\
\cline { 3 - 4 } Medium & RL $(\%)$ & $4^{\circ} \mathrm{C}$ & $25^{\circ} \mathrm{C}$ & $37^{\circ} \mathrm{C}$ \\
\hline Nutrient broth & 0.05 & $24.5^{\mathrm{A}, \mathrm{a}}$ & $17.8^{\mathrm{B}, \mathrm{a}}$ & $21.9^{\mathrm{A}, \mathrm{a}}$ \\
& 0.1 & $18.8^{\mathrm{A}, \mathrm{a}}$ & $34.7^{\mathrm{B}, \mathrm{b}}$ & $24.2^{\mathrm{A}, \mathrm{a}}$ \\
& 0.25 & $16.9^{\mathrm{A}, \mathrm{a}}$ & $29.6^{\mathrm{B}, \mathrm{b}}$ & $22.7^{\mathrm{A}, \mathrm{a}}$ \\
& 0.5 & $17.9^{\mathrm{A}, \mathrm{a}}$ & $22.8^{\mathrm{A}, \mathrm{a}}$ & $13.6^{\mathrm{B}, \mathrm{b}}$ \\
Skim milk & $16.9^{\mathrm{A}, \mathrm{a}}$ & $20.3^{\mathrm{A}, \mathrm{a}}$ & $5.3^{\mathrm{B}, \mathrm{b}}$ \\
& 2 & $2.8^{\mathrm{A}, \mathrm{b}}$ & $-5.9^{\mathrm{B}, \mathrm{c}}$ & $10.6^{\mathrm{C}, \mathrm{b}}$ \\
& 0.05 & $88.9^{\mathrm{A}, \mathrm{a}}$ & $86.2^{\mathrm{A}, \mathrm{a}}$ & $85.2^{\mathrm{A,a}}$ \\
& 0.1 & $87.3^{\mathrm{A}, \mathrm{a}}$ & $86.9^{\mathrm{A}, \mathrm{a}}$ & $76.6^{\mathrm{A}, \mathrm{a}}$ \\
& 0.25 & $83.3^{\mathrm{A}, \mathrm{a}}$ & $86.6^{\mathrm{A}, \mathrm{a}}$ & $83.2^{\mathrm{A}, \mathrm{a}}$ \\
& 0.5 & $82.9^{\mathrm{A}, \mathrm{a}}$ & $85.5^{\mathrm{A}, \mathrm{a}}$ & $81.4^{\mathrm{A}, \mathrm{a}}$ \\
& 1 & $78.6^{\mathrm{A}, \mathrm{a}}$ & $84.2^{\mathrm{A}, \mathrm{a}}$ & $78.6^{\mathrm{A}, \mathrm{a}}$ \\
& 2 & $77.6^{\mathrm{A}, \mathrm{b}}$ & $80.6^{\mathrm{A}, \mathrm{a}}$ & $70.0^{\mathrm{B}, \mathrm{b}}$ \\
\hline
\end{tabular}

${ }^{\mathrm{A}-\mathrm{C}}$ In each row the values followed by the same capital letter do not differ significantly $(P<0.05)$.

${ }^{\mathrm{a}-\mathrm{c}}$ In each column the values followed by the same lowercase letter do not differ significantly $(P<0.05)$.

tested. Rhamnolipids promote an effective removal of biofilms grown in skim milk, reaching $86.9 \%$ reduction at $25^{\circ} \mathrm{C}$. In comparison to the results observed for nutrient broth, the variations on RL concentration and on the temperature of treatment had no significant effect on disruption activity of the milk-based biofilms (Table 1). Biofilm removal by surfactants involves the weakening of bacteria-surface and bacteria-bacteria interactions due to reducing surface or interfacial tensions, thus favoring dispersion (McLandsborough et al., 2006; Rendueles and Ghigo, 2012). The interaction of surfactant molecules with polymers also involves hydrophobic and electrostatic forces (Banipal et al., 2014); therefore, interaction depends on the nature and composition of polymeric material. Considering these statements, the effect of RL treatment on biofilm hydrophobicity and matrix composition was evaluated.

\section{Contact Angle Measurements}

The surface of biofilms and polystyrene samples were submitted to contact angle measurements using water as a solvent. The results showed that polystyrene is a hydrophobic material with a water contact angle of $83^{\circ}$; after biofilm establishment the contact angle was reduced, possibly due to the presence of matrix carbohydrates and proteins that increase hydrophilic character or wettability (Table 2). Biofilms established in milk were more hydrophilic than those formed in nutrient broth. After RL treatment, an expressive decrease in hydrophobicity was observed for both biofilm types, showing that surfactant molecules reduces surface or interfacial tension, increasing affinity of biofilms with water. Although biofilm hydrophobicity was significantly reduced by RL, the disruption activity was much more pronounced in milk-based biofilms, as shown in Table 1.

\section{Biofilm Biochemical Characterization}

The main structural components of biofilm matrix are polysaccharides, proteins, lipids, and nucleic acids (Flemming and Wingender, 2010). Aiming to correlate the matrix composition of biofilms with the RL disruption activity observed, the biofilm extracellular matrix was analyzed and the results are shown in Table 3 . The

Table 2. Contact angle measurements of Staphylococcus aureus biofilms before and after treatment with rhamnolipids (RL)

\begin{tabular}{llccc}
\hline Sample & Medium & $\begin{array}{c}\text { Temperature } \\
\left({ }^{\circ} \mathrm{C}\right)\end{array}$ & $\begin{array}{c}\text { RL } \\
(\%)\end{array}$ & $\begin{array}{c}\text { Contact angle } \\
\left({ }^{\circ}\right)\end{array}$ \\
\hline Polystyrene & - & - & - & $83.51 \pm 2.94$ \\
Control & $\mathrm{NB}^{2}$ & 25 & $0^{3}$ & $58.22 \pm 6.64$ \\
Treatment & $\mathrm{NB}$ & 25 & 0.1 & $12.27 \pm 5.57$ \\
Control & Skim milk & 4 & $0^{3}$ & $35.35 \pm 6.68$ \\
Treatment & Skim milk & 4 & 0.05 & $14.61 \pm 4.87$ \\
\hline
\end{tabular}

${ }^{1}$ Average of at least 6 drops $\pm \mathrm{SD}$.

${ }^{2} \mathrm{NB}=$ nutrient broth

${ }^{3}$ Controls were treated with sterile distilled water 
Table 3. Biochemical composition of Staphylococcus aureus biofilm matrix before and after treatment with rhamnolipids (RL)

\begin{tabular}{lcccrr}
\hline Medium/sample & $\begin{array}{c}\text { Temperature } \\
\left({ }^{\circ} \mathrm{C}\right)\end{array}$ & $\begin{array}{c}\mathrm{RL} \\
(\%)\end{array}$ & $\begin{array}{c}\text { Carbohydrates } \\
\left(\mu \mathrm{g} / \mathrm{mg}_{\text {biof }}\right)\end{array}$ & $\begin{array}{r}\text { Proteins }^{1} \\
\left(\mu \mathrm{g} / \mathrm{mg}_{\text {biof }}\right)\end{array}$ & $\begin{array}{c}\mathrm{DNA}^{1} \\
\left(\mu \mathrm{g} / \mathrm{mg}_{\text {biof }}\right) \times 10^{-3}\end{array}$ \\
\hline $\mathrm{NB}^{2} /$ Control & 25 & - & $0.22 \pm 0.00$ & $1.03 \pm 0.21$ & $137.00 \pm 0.02$ \\
$\mathrm{NB} /$ Treatment & 25 & 0.1 & $0.16 \pm 0.03$ & $0.85 \pm 0.19$ & $15.00 \pm 0.01$ \\
$\mathrm{SM}^{3}$ Control & 4 & - & $5.48 \pm 0.11$ & $1.67 \pm 0.48$ & $100.00 \pm 0.02$ \\
$\mathrm{SM} /$ Treatment & 4 & 0.05 & $0.56 \pm 0.02$ & $0.65 \pm 0.28$ & $7.00 \pm 0.02$ \\
\hline
\end{tabular}

${ }^{1}$ Values correspond to the mean of at least 2 independent experiments \pm SD. $\mathrm{mg}_{\text {biof }}=\mathrm{mg}$ of biofilm.

${ }^{2} \mathrm{NB}=$ nutrient broth.

${ }^{3} \mathrm{SM}=$ skim milk.

main difference was the carbohydrate content of biofilms established in milk were higher than in nutrient broth biofilms. As discussed, the milk-based biofilms showed the highest hydrophilic character, possibly due to having the highest carbohydrate percentage. The protein and DNA contents of matrix were similar for both media, and after RL treatment their concentrations were also similarly reduced. More carbohydrates were removed after RL treatment on milk biofilm compared with nutrient broth. It is possible RL interacts with carbohydrates, promoting their solubilization or mobilization, thus favoring the detachment of biofilms. Studies regarding the interaction of RL biosurfactants with Pseudomonas aeruginosa biofilms revealed that, after RL treatment, the carbohydrate and protein content decreased by 31.6 and $79.6 \%$, respectively (Kim et al., 2015), indicating a selective interaction of RL with proteins. In our study, the carbohydrates of milk-based biofilm were selectively removed; from these data, we can conclude that matrix composition has an important influence on RL disruption activity.

Fagerlund et al. (2016) also observed a variable composition on the biofilm matrix of food-associated Staphylococcus strains. The strains with high protein content in biofilm matrix were more susceptible to benzalkonium chloride than strains with carbohydratebased matrix. However, biofilms from all strains showed similar levels of detachment after exposure to alkaline chlorine.

\section{DLS Data for RL in Solution}

The DLS analysis was performed to evaluate the molecular aggregation, size, and number of surfactant particles under the different conditions of temperature and surfactant concentration employed. The scattering intensity distributions curves (Figure $1 \mathrm{~A}, \mathrm{C}, \mathrm{E}$ ) shows the predominance of 2 main distinctive groups of aggregates: one ranging from 1 to $10 \mathrm{~nm}$ and other from 100 to $1,000 \mathrm{~nm}$, suggesting the coexistence of premicellar, micellar, or vesicular aggregate forms (Champion et al., 1995). At the lowest RL concentration (0.05\%) studied, it is possible to observe the presence of particles with an average diameter of $10 \mathrm{~nm}$ that gradually disappears; the intensity of larger aggregates also increases with temperature. This behavior is expected once increasing temperature accelerates molecular vibrations and the interconversion of aggregate forms. Figure 1 (B,D,F) shows that the distribution by number of particles in solution remains similar, with a predominance of particles between 0.5 to $20 \mathrm{~nm}$, reinforcing the idea of molecular rearrangement at the different concentrations and temperatures. The PDI tends to decrease with increasing of RL concentration and temperature (Table 4); at lower RL concentration, the heterogeneity of the molecular sizes present is higher, and these results are in agreement with scattering intensity and particle number distributions curves presented in Figure 1. The critical micelle concentration (CMC) of the RL was estimated at $40 \mathrm{mg} / \mathrm{L}(0.004 \%)$; hence, all concentrations used were above the CMC of the surfactant. Mediumsize spherical vesicles, ranging from 50 to $250 \mathrm{~nm}$, were reported to form spontaneously at RL concentrations above CMC (Pornsunthorntawee et al., 2009); however, at higher concentrations $(>2,500 \mathrm{mg} / \mathrm{L})$, only large spherical vesicles $(>250 \mathrm{~nm})$ were observed.

Another study using DLS for RL produced by a $P$. aeruginosa mutant (MIG-N146) reported the presence of 2 major groups of molecular aggregates with hydrodynamic diameter values changing from 80 to 150 and 700 to $1,300 \mathrm{~nm}$ at increasing RL concentrations (Guo et al., 2009). Compared with the current work, the differences observed may be attributed to composition and purity of the RL surfactant.

\section{Microscopy of Biofilms}

Biofilms established in milk and culture medium were observed under scanning electron microscopy and confocal laser scanning microscopy before and after treatment with RL. Scanning electron microscopy analysis shows that the biofilm structure differs according to the substrate. Milk biofilms show a great amount of matrix and cell aggregates compared to biofilms established on 

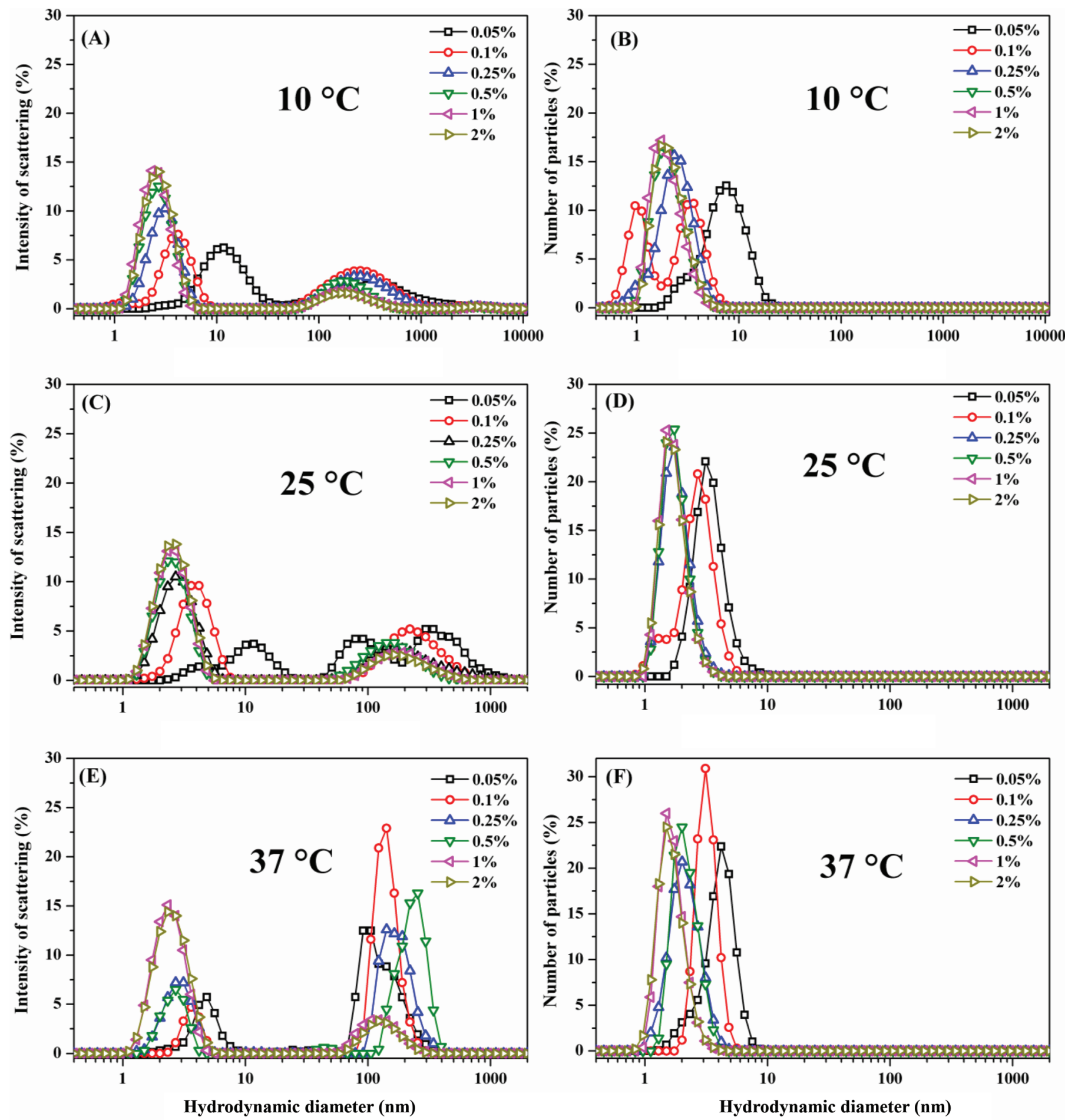

Figure 1. Scattering light intensity and number of particles distribution curves of rhamnolipid solutions at different concentrations and temperatures. Color version available online.

nutrient broth, which showed small bacterial clusters and scant matrix (Figure 2 A, C). Pagedar et al. (2010) reported the biofilm formation by dairy $S$. aureus isolates was influenced by culture medium composition, showing that diluted rather than rich nutrient media stimulate biofilm formation due to nutritional stress. In our study, both rich media sustain sessile growth; however, milk promotes an abundant biofilm. After RL 



Figure 2. Scanning electron microscopy pictures of Staphylococcus aureus biofilms grown in nutrient broth and skim milk before (A and C) and after (B and D) treatment with $0.1 \%$ rhamnolipids at $25^{\circ} \mathrm{C}$.

treatment, it was possible to observe the removal of attached bacteria and matrix (Figure $2 \mathrm{~B}, \mathrm{D}$ ), especially on milk-based biofilms, supporting the data previously described (Table 1).

The effect of RL on milk-based biofilms was demonstrated by confocal microscopy (Figure 3). Control biofilm was dense, with thickness of about $12 \mu \mathrm{m}$ and a predominance of living cells; after RL treatment, a marked disruption of matrix was observed and the biofilm thickness was reduced to $5 \mu \mathrm{m}$. The 3 -dimensional picture shows regions with scarce presence of cells due to surfactant removal; some dead cells were also observed, suggesting a possible inhibitory effect of RL. Some clinical strains of $S$. aureus have already demon-

Table 4. Polydispersity index ${ }^{1}$ for rhamnolipid (RL) biosurfactant solutions at different concentrations and temperatures

RL concentration

\begin{tabular}{lcccccc}
\cline { 2 - 6 } Temperature & $0.05 \%$ & $0.1 \%$ & $0.25 \%$ & $0.5 \%$ & $1 \%$ & $2 \%$ \\
\hline $10^{\circ} \mathrm{C}$ & $0.49 \pm 0.06$ & $0.39 \pm 0.06$ & $0.36 \pm 0.07$ & $0.34 \pm 0.03$ & $0.26 \pm 0.03$ & $0.26 \pm 0.03$ \\
$25^{\circ} \mathrm{C}$ & $0.45 \pm 0.09$ & $0.26 \pm 0.02$ & $0.25 \pm 0.06$ & $0.31 \pm 0.07$ & $0.31 \pm 0.01$ & $0.26 \pm 0.04$ \\
$37^{\circ} \mathrm{C}$ & $0.40 \pm 0.06$ & $0.28 \pm 0.05$ & $0.36 \pm 0.07$ & $0.35 \pm 0.02$ & $0.15 \pm 0.07$ & $0.13 \pm 0.03$ \\
\hline
\end{tabular}

${ }^{1}$ Polydispersity index was obtained from dynamic light scattering data. Data represent the mean of at least 5 measurements \pm SD. 

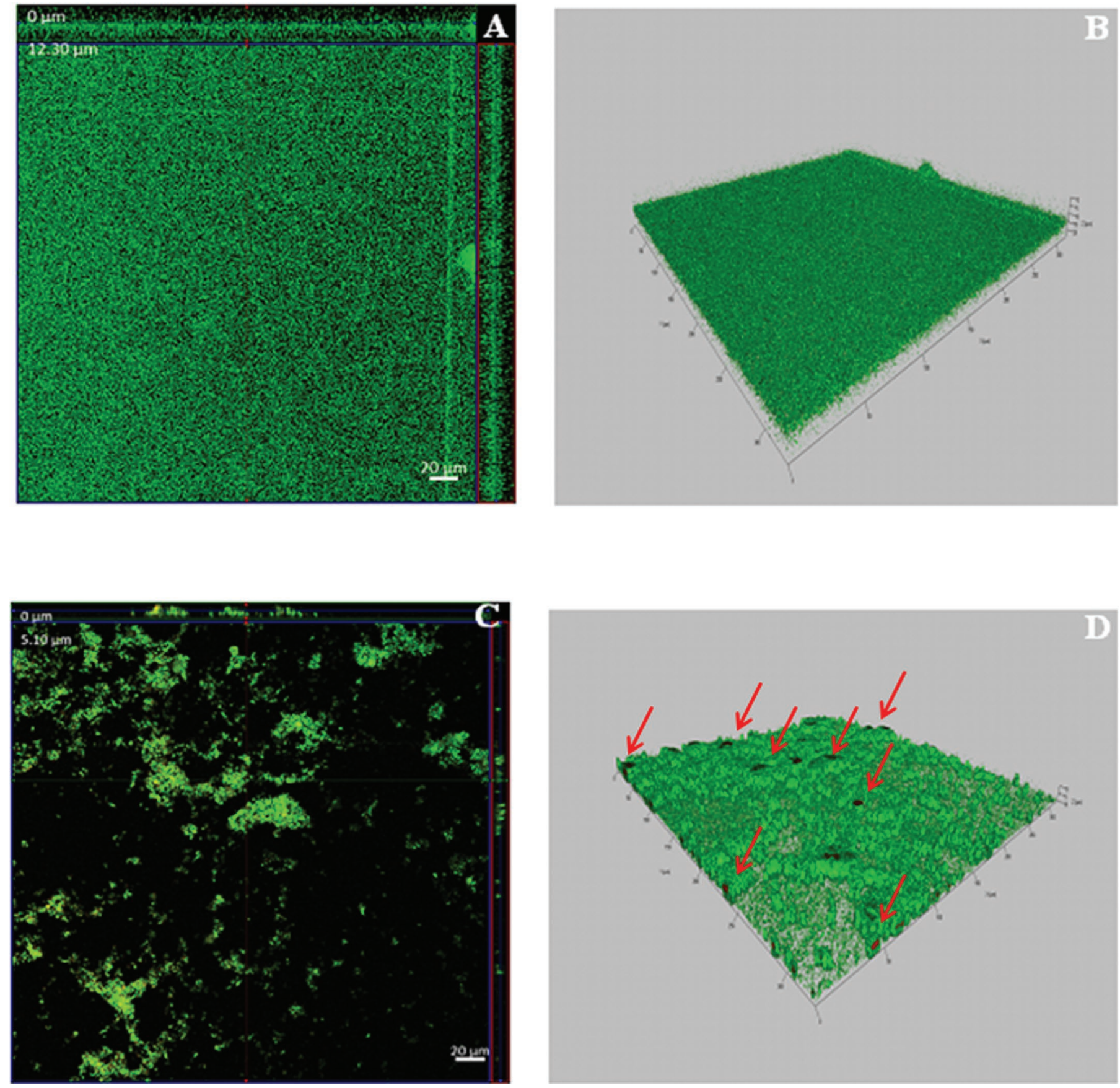

Figure 3. Confocal microscopy of biofilms established in skim milk. The pictures show orthogonal (left) and 3-dimensional (right) images of control (A, B) and biofilm treated with $0.05 \%$ rhamnolipids at $4^{\circ} \mathrm{C}$ for $2 \mathrm{~h}(\mathrm{C}, \mathrm{D})$. Fluorescence staining shows live cells in green and dead cells in red. The arrows indicate the dead cells. Color version available online.

strated sensitivity to RL in planktonic form (Samadi et al., 2012); after longer contact, a marked antimicrobial effect of RL could also possibly be observed in biofilms. Antimicrobial activity of RL was associated with alterations on cell membrane permeability, and their combination with nisin showed synergistic effects against the food pathogen L. monocytogenes (Magal- hães and Nitschke, 2013). Thus, RL may also represent a new tool to combat $S$. aureus in food.

In this work we evaluated the ability of RL surfactants to disrupt or remove biofilms of $S$. aureus. The biofilms were grown in culture medium or skim milk and RL treatment was performed at different surfactant concentrations and temperatures. The biofilms 
formed in nutrient broth were more resistant to RL than milk-based biofilms. The DLS analysis of RL solutions revealed that temperature and concentration affects RL molecular size distribution; however, 2 main groups of molecular aggregates were present in all the conditions tested. Although no direct correlation between molecular aggregation and removal of biofilm was observed at the range of RL concentration and temperature tested, the data obtained suggest that the increase in PDI enhance the removal or disruption of biofilms (Table 4), principally when they were established in nutrient broth (Table 1). At lower RL concentrations and temperatures, the presence of small aggregates and monomers may facilitate the disruption activity of the biosurfactant, whereas increasing micellar aggregates present at higher RL concentrations and temperatures may reduce interaction with biofilms. Considering the results obtained, it can be hypothesized that RL disruption activity probably involves a mobilization mechanism, which is characterized by a reduction of interfacial and surface tension, capillary forces, and contact angle, predominantly owing to the presence of surfactant monomers in solution (Urum and Pekdemir, 2004).

Rhamnolipids have anionic character at neutral $\mathrm{pH}$ but can also behave as nonionic due to the protonation of carboxylic groups at acidic conditions (Lebrón-Paler and Pemberton, 2006); therefore, $\mathrm{pH}$ has an important effect on RL molecular aggregation due to the repulsion of adjacent hydrophilic heads at increased $\mathrm{pH}$ values that disfavors formation of large lamellar structures (Pornsunthorntawee et al., 2009). In our work, RL solution was adjusted to $\mathrm{pH} 7$; thus, the anionic form predominates. The presence of charged groups in biofilm surface promotes repulsive or attractive ionic interactions with RL aggregates and monomers and may account for the different results observed with the different substrates. Contact angle measurements demonstrated that milk-based biofilms were more hydrophilic than nutrient broth biofilms and, possibly, the predominance of polar groups enhanced their interaction with RL molecules and their subsequent removal. The presence of higher carbohydrate contents in milk biofilms may account for the higher disruption activity observed.

The results obtained revealed that disruption activity of RL is not only species-specific (Gomes and Nitschke, 2012) but also nutrient- specific and dependent on biofilm matrix composition. Staphylococcus aureus biofilms established in skim milk were significantly reduced using RL at a low concentration and temperature. These findings suggest potential application of RL in milk (dairy) processing industries where low temperatures are habitually applied. Moreover, preliminary studies demonstrated the inhibitory activity of RL in S. aureus biofilms, reducing, on average, $25 \%$ of cell viability at $4^{\circ} \mathrm{C}$ after $2 \mathrm{~h}$ of treatment (data not shown), which reinforces the prospective application of RL surfactants to control this important food pathogen.

Further work should include testing RL on established biofilms formed on food contact surfaces and evaluating antimicrobial activity of RL against planktonic and sessile $S$. aureus food strains. Likewise, biofilm treatment under flow conditions could be compared with the static treatment used in this work, and, alternatively, a combination of static or flow conditions would be more efficient to disrupt biofilms. The chemical elucidation of matrix components could contribute to a better understanding of the mechanisms involved in biofilm disruption by RL.

\section{ACKNOWLEDGMENTS}

We thank the following groups from University of São Paulo (USP), Brazil: The Analytical Central (CAQI) of São Carlos Institute of Chemistry (IQSC) for scanning electron microscopy facilities; group of Polymers "Prof. Bernhard Gross" of the Institute of Physics of São Carlos (IFSC) for the contact angle analysis. Molecular Biophysics Group at IQSC, in particular to Marcel Tabak, for help on the dynamic light scattering technique. Thanks go to the group of Biochemistry of the Faculty of Pharmaceutical Sciences of Ribeirão Preto (FCFRP), in particular to Ana Cristina Morseli Polizello and Michael Osungunna, for their help in biofilm matrix characterization. We also thank FAPESP (Fundação de Amparo à Pesquisa do Estado de São Paulo) Grant no. 2015/22414-7 for financial support.

\section{REFERENCES}

Abdallah, M., C. Benoliel, D. Drider, P. Dhulster, and N. E. Chihib. 2014. Biofilm formation and persistence on abiotic surfaces in the context of food and medical environments. Arch. Microbiol. 196:453-472.

Araújo, L. V., C. R. Guimarães, R. L. S. Marquita, V. M. J. Santiago, M. P. Souza, M. Nitschke, and D. M. G. Freire. 2016. Rhamnolipid and surfactin: Anti-adhesion/antibiofilm and antimicrobial effects. Food Contr. 63:171-178.

Argudín, M. A., M. C. Mendoza, and M. R. Rodicio. 2010. Food poisoning and Staphylococcus aureus enterotoxins. Toxins (Basel) 2:1751-1773.

Banat, I. M., M. A. D. Rienzo, and G. A. Quinn. 2014. Microbial biofilms: Biosurfactants as antibiofilm agents. Appl. Microbiol. Biotechnol. 98:9915-9929.

Banipal, T. S., H. Kaur, P. K. Banipal, and A. K. Sood. 2014. Effect of head groups, temperature, and polymer concentration on surfactant-polymer interactions. J. Surfactants Deterg. 17:1181-1191.

CDC. 2013. Surveillance for Foodborne Disease Outbreaks United States. Annual Report. Accessed Aug. 21, 2016. http://www.cdc .gov/foodsafety/pdfs/foodborne-disease-outbreaks-annual-report -2013-508c.pdf/. 
Champion, J. T., J. C. Gilkey, H. Lamparski, J. Reitrer, and R. M. Miller. 1995. Electron microscopy of rhamnolipid (biosurfactant) morphology: Effects of $\mathrm{pH}$, cadmium, and octadecane. J. Colloid Interface Sci. 170:569-574.

Costerton, J. W., P. S. Stewart, and E. P. Greenberg. 1999. Bacterial biofilms: A common cause of persistent infections. Science 284:1318-1322.

Donlan, R. M., and J. W. Costerton. 2002. Biofilms: Survival mechanisms of clinically relevant microorganisms. Clin. Microbiol. Rev. 15:167-193.

Dubois, M., K. A. Gilles, J. K. Hamilton, P. A. Rebers, and F. Smith. 1956. Colorimetric method for determination of sugars and related compounds. Anal. Chem. 28:350-356.

Fagerlund, A., S. Langsrud, E. Heir, M. I. Mikkelsen, and T. Møretrø. 2016. Biofilm matrix composition affects the susceptibility of food associated staphylococci to cleaning and disinfection agents. Front. Microbiol. 7:856. https://doi.org/10.3389/fmicb.2016.00856.

Flemming, H. C., and J. Wingender. 2010. The biofilm matrix. Nat. Rev. Microbiol. 8:623-633.

Gomes, M. Z. V., and M. Nitschke. 2012. Evaluation of rhamnolipid and surfactin to reduce the adhesion and remove biofilms of individual and mixed cultures of food pathogenic bacteria. Food Contr. 25:441-447.

Guo, Y. P., Y. Y. Hu, R. R. Gu, and H. Lin. 2009. Characterization and micellization of rhamnolipidic fractions and crude extracts produced by Pseudomonas aeruginosa mutant MIG-N146. J. Colloid Interface Sci. 331:356-363.

Hennekinne, J. A., M. L. De Buyser, and S. Dragacci. 2012. Staphylococcus aureus and its food poisoning toxins: characterization and outbreak investigation. FEMS Microbiol. Rev. 36:815-836.

Kadariya, J., T. C. Smith, and D. Thapaliya. 2014. Staphylococcus aureus and staphylococcal food-borne disease: an ongoing challenge in public health. BioMed Res. Int. 2014:827965. https://doi.org/ $10.1155 / 2014 / 827965$

Kim, L. H., Y. Jung, H. W. Yu, K. J. Chae, and I. S. Kim. 2015. Physicochemical interactions between rhamnolipids and Pseudomonas aeruginosa biofilm layers. Environ. Sci. Technol. 49:3718-3726.

Lebrón-Paler, A., and J. E. Pemberton. 2006. Determination of the acid dissociation constant of the biosurfactant monorhamnolipid in aqueous solution by potentiometric and spectroscopic methods. Anal. Chem. 78:7649-7658.

Magalhães, L., and M. Nitschke. 2013. Antimicrobial activity of rhamnolipids against Listeria monocytogenes and their synergistic interaction with nisin. Food Contr. 29:138-142.

Marchand, S., J. D. Block, V. D. Jonghe, A. Coorevits, M. Heyndrickx, and L. Herman. 2012. Biofilm formation in milk production and processing environments; influence on milk quality and safety. Compr. Rev. Food Sci. Food Saf. 11:133-147.

McLandsborough, L., A. Rodriguez, D. Pérez-Conesa, and J. Weiss. 2006. Biofilms: At the interface between biophysics and microbiology. Food Biophys. 1:94-114.

Mireles, J. R., II, A. Toguchi, and R. M. Harshey. 2001. Salmonella enterica serovar typhimurium swarming mutants with altered biofilm-forming abilities: Surfactin inhibits biofilm formation. J. Bacteriol. 183:5848-5854.

Newell, D. G., M. Koopmans, L. Verhoef, E. Duizer, A. Aidara-Kane, H. Sprong, M. Opsteegh, M. Langelaar, J. Threfall, F. Scheutz, J.
Van der Giessen, and H. Kruse. 2010. Food-borne diseases-The challenges of 20 years ago still persist while new ones continue to emerge. Int. J. Food Microbiol. 139:S3-S15.

Pagedar, A., J. Singh, and V. K. Batish. 2010. Surface hydrophobicity, nutritional contents affect Staphylococcus aureus biofilms and temperature influences its survival in preformed biofilms. J. Basic Microbiol. 50:S98-106.

Pornsunthorntawee, O., S. Chavadej, and R. Rujiravanit. 2009. Solution properties and vesicle formation of rhamnolipid biosurfactants produced by Pseudomonas aeruginosa SP4. Colloids Surf. B Biointerfaces 72:6-15.

Raja, A. F., F. Ali, I. A. Khan, A. S. Shawl, D. S. Arora, B. A. Shah, and S. C. Taneja. 2011. Antistaphylococcal and biofilm inhibitory activities of acetyl-11-keto- $\beta$-boswellic acid from Boswellia serrata. BMC Microbiol. 11:54.

Rendueles, O., and J. M. Ghigo. 2012. Multi-species biofilms: How to avoid unfriendly neighbors. FEMS Microbiol. Rev. 36:972-989.

Sadekuzzaman, M., S. Yang, M. F. R. Mizan, and S. D. Ha. 2015 Current and recent advanced strategies for combating biofilms. Compr. Rev. Food Sci. Food Saf. 14:491-509.

Samadi, N., N. Abadian, R. Ahmadkhaniha, F. Amini, D. Dalili, N. Rastkari, E. Safaripour, and F. A. Mohseni. 2012. Structural characterization and surface activities of biogenic rhamnolipid surfactants from Pseudomonas aeruginosa isolate MN1 and synergistic effects against methicillin-resistant Staphylococcus aureus. Folia Microbiol. (Praha) 57:501-508

Satpathy, S., S. K. Sen. S. Pattanaik, and S. Raut. 2016. Review on bacterial biofilm: An universal cause of contamination. Biocatal. Agric. Biotechnol. 7:56-66.

Shakerifard, P., F. Gancel, P. Jacques, and C. Faille. 2009. Effect of different Bacillus subtilis lipopeptides on surface hydrophobicity and adhesion of Bacillus cereus 98/4 spores to stainless steel and Teflon. Biofouling 25:533-541.

Simões, M., L. C. Simões, and M. J. Vieira. 2010. A review of current and emergent biofilm control strategies. LWT Food Sci. Technol. $43: 573-583$

Srey, S., I. K. Jahid, and S. D. Ha. 2013. Biofilm formation in food industries: A food safety concern. Food Contr. 31:572-585.

SVS. 2015. Doenças transmitidas por alimentos. Accessed Sep. 20, 2016. http://u.saude.gov.br/images/pdf/2015/novembro/09/ Apresenta-o-dados-gerais-DTA-2015.pdf/.

Urum, K., and T. Pekdemir. 2004. Evaluation of biosurfactants for crude oil contaminated soil washing. Chemosphere 57:1139-1150.

USDA. 2013. Foodborne illness and disease. Accessed Aug. 10, 2016. http://www.fsis.usda.gov/wps/portal/fsis/topics/food-safety -education/get-answers/food-safety-fact-sheets/foodborne-illness -and-disease/foodborne-illness-what-consumers-need-to-know/ct index/.

WHO. 2016. Foodborne diseases. Accessed Jul. 13, 2016. http://www .who.int/topics/foodborne_diseases/en/.

Yang, L., Y. Liu, H. Wu, Z. Song, N. Høiby, S. Molin, and M. Givskov. 2012. Combating biofilms. FEMS Immunol. Med. Microbiol. 65:146-157.

Zeraik, A. E., and M. Nitschke. 2010. Biosurfactants as agents to reduce adhesion of pathogenic bacteria to polystyrene surfaces: effect of temperature and hydrophobicity. Curr. Microbiol. 61:554-559. 